\title{
Rebrota de cepas de Acacia mearnsii em diferentes idades, épocas do ano e alturas de corte
}

\author{
Edison Rogério Perrando( ${ }^{(1)}$ e Maisa Pimentel Martins Corder ${ }^{(1)}$
}

\author{
(1)Universidade Federal de Santa Maria, Dep. de Engenharia Florestal, CEP 97105-900 Santa Maria, RS. E-mail: eperran@terra.com.br, \\ mcorder@ccr.ufsm.br
}

\begin{abstract}
Resumo - O objetivo deste trabalho foi avaliar o efeito da idade, da época do ano e da altura de corte sobre a capacidade de rebrota de cepas de Acacia mearnsii De Wild. O trabalho foi conduzido em delineamento de blocos ao acaso e parcelas subdivididas no tempo. Em árvores de quatro e sete anos, foram avaliadas as alturas de corte de 0,15; 0,30; 0,45; 0,60; 1,2 e 2 m aos 15, 30, 45, 60, 75 e 90 dias depois do corte, nas quatro estações do ano. Obteve-se interação significativa entre a altura de corte e a época de avaliação, em ambas as idades avaliadas. As maiores médias, quanto ao número de brotações por cepa, foram constatadas a 1,2 e 2 m de altura, na idade de quatro anos. Elevados porcentuais de mortalidade foram registrados em cepas com sete anos, independentemente da altura de corte. A capacidade de rebrota em cepas de acácia-negra é estimulada, quando o corte é realizado no período entre o outono e a primavera. O verão é a estação menos adequada à rebrota de cepas dessa espécie.
\end{abstract}

Termos para indexação: acácia-negra, altura de cepa, época de corte, silvicultura.

\section{Resprouting of Acacia mearnsii stumps under different ages, seasons and cut heights}

\begin{abstract}
The objective of this work was to evaluate the effect of age, time of the year and cut height on the resprouting capacity of Acacia mearnsii De Wild. stumps. The work was conducted in stands of four and seven years of age, in randomized blocks design and time subdivided plots. Different cut heights $(0.15 ; 0.30 ; 0.45 ; 0.60$; 1.2 and $2 \mathrm{~m}$ ), and evaluation times (15, 30, 45, 60, 75 and 90 days after cutting), in the four seasons of the year were evaluated. A significant interaction between cut height and evaluation time was found in both ages. The higher averages due to stumps in each strain were verified in 1.2 and $2 \mathrm{~m}$ height, in the age of four years. High death percentages were registered in seven years-old stumps, independently of cut height. The resprouting capacity of black wattle stumps is stimulated when cut is conducted between autumn and spring; summer is the least suitable season to stumps resprouting of this specie.
\end{abstract}

Index terms: black wattle, stump height, time of cutting, forestry.

\section{Introdução}

Intrínseca ao genótipo de algumas espécies de porte arbóreo, a passagem da fase juvenil para a fase adulta de uma planta gera mudanças relacionadas, principalmente, ao hábito de crescimento, como o vigor vegetativo e a restauração da capacidade de enraizamento (Wendling \& Xavier, 2001). Segundo Higashi et al. (2000), o uso do termo maturação, considerado como processo que não ocorre na mesma velocidade em todas as partes da planta, estaria relacionado à idade ontogenética. Sabe-se, ainda, que o controle fisiológico relacionado à maturação pode ser modificado por qualquer tipo de estresse sofrido pela planta, podendo ser quantificado pela capacidade e intensidade de rebrota de cepas depois do corte, ou afetadas por fogo, geada ou insetos (Higa \& Sturion, 1997).

Atualmente, uma das estratégias de clonagem de espécies florestais tem sido o corte e a obtenção de brotações de cepa, como forma de reversão do estado adulto ao estado juvenil da planta. A realização do corte raso de árvores adultas, para induzir o crescimento de brotações juvenis, e a manutenção da juvenilidade por podas sucessivas visam a aumentar quantitativa e qualitativamente a produção de propágulos, na região basal do tronco (Hackett, 1988). Esta prática tem sido amplamente empregada na produção de mudas por 
estaquia, em espécies do gênero Eucalyptus, conferindo-lhe importante capacidade de recuperação depois do corte de sua parte aérea (Reis \& Reis, 1997). Contudo, vários estudos abordam alguns fatores como preponderantes sobre a capacidade de rebrota e sobrevivência de cepas de espécies arbóreas, entre eles a idade, a altura de corte da planta, os níveis de substâncias de reserva alocados e, sobretudo, o efeito das variações climáticas verificadas ao longo do ano (Sakai \& Sakai, 1998; Nair et al., 2001; Luoga et al., 2004; Tewari et al., 2004).

Entre as espécies florestais que compõem o cenário silvicultural no país (tradicionalmente as do gênero Eucalyptus e Pinus), a Acacia mearnsii De Wild., popularmente conhecida como acácia-negra, tem assumido, nos últimos anos, relevante expressão comercial ante as relações internas e externas de mercado estabelecidas pelas empresas do setor florestal.

Compondo um maciço florestal de aproximadamente 160 mil hectares, concentrado no Sul do Brasil, do qual participam cerca de 10 mil famílias de pequenos produtores rurais, as florestas de $A$. mearnsii são fonte de matéria-prima para a indústria coureira (tanino extraído da casca), celulose e aglomerados (madeira), entre outras, além de sua contribuição ambiental como recuperadora de solos (Fowler et al., 1999). No entanto, o crescente cultivo de acácia-negra é ainda estabelecido a partir de mudas produzidas por sementes, o que confere alta variabilidade genética entre os indivíduos do povoamento e, conseqüentemente, na produtividade da floresta. Resultados inerentes à capacidade de regeneração dessa espécie por meio de cepas e sua viabilidade como método de clonagem, nas condições brasileiras, são ainda incipientes.

Este trabalho teve por objetivo avaliar a capacidade de rebrota e sobrevivência de cepas de A. mearnsii, sob a influência de fatores como a idade, época do ano e altura de corte das árvores.

\section{Material e Métodos}

Este trabalho foi conduzido em plantios comerciais de acácia-negra, pertencentes à empresa florestal Agroseta S.A., localizados no Município de Butiá (RS), a $30^{\circ} 7^{\prime} 12^{\prime \prime} S$ e $51^{\circ} 57^{\prime} 45^{\prime \prime} O$. Com altitude de $100 \mathrm{~m}$, o clima da região é do tipo Cfa, com temperatura média do mês mais quente de $24^{\circ} \mathrm{C}$ e do mês mais frio de $13^{\circ} \mathrm{C}$.
A precipitação média anual é de $1.400 \mathrm{~mm}$. A floresta foi estabelecida a partir de mudas produzidas por sementes, no espaçamento de 3x1,5 m, em Argissolo Vermelho distrófico.

Foram selecionados, para o trabalho, povoamentos com idade de quatro e sete anos. Em cada um dos povoamentos, foram instalados quatro testes de rebrota (na primavera, no verão, no outono e no inverno), nos quais se avaliou o comportamento de cepas mediante o corte das árvores em diferentes alturas. As avaliações foram definidas aos 15, 30, 45, 60, 75 e 90 dias depois do corte, ao longo de cada uma das estações do ano. Sistematicamente, estabeleceu-se uma bordadura, com aproximadamente $15 \mathrm{~m}$, na área adjacente aos testes. Foi realizado o monitoramento das áreas, mediante procedimentos que envolveram o coroamento das cepas depois do corte, a fertilização e o controle de pragas. Foram realizadas podas de manutenção da brotação em cada um dos testes conduzidos, conforme a época do ano e o seu desenvolvimento, de modo a manter a juvenilidade desse material para possíveis testes clonais em fase posterior.

Empregou-se o delineamento de blocos ao acaso, com parcelas subdivididas no tempo, segundo o esquema fatorial $6 \times 6$, constituído de seis alturas de corte $(0,15$; 0,30; 0,45; 0,60; 1,20 e $2 \mathrm{~m}$ acima do solo) e seis épocas de avaliação (15, 30 4 45, 60, 75 e 90 dias depois do corte), para cada uma das estações do ano (primavera, verão, outono e inverno) e em cada uma das idades do povoamento (quatro e sete anos). Foram utilizadas seis plantas na unidade experimental e seis repetições para cada altura de corte, num total de 216 árvores cortadas em cada um dos oito testes.

As variáveis analisadas foram a sobrevivência e o número de brotações por cepa. A contagem do número de brotações foi cumulativa ao longo do programa de avaliações depois do corte das árvores. Os dados das medições foram transformados em $(x+0,5)^{0,5}$ e submetidos à análise de variância (SigmaStat 2.0 Statistical Software) e a testes estatísticos complementares, para ajuste de modelos matemáticos de predição (SAS Statistical Analysis System).

\section{Resultados e Discussão}

O número de brotações por cepa, em função da idade do povoamento e das estações do ano nas quais o 
trabalho foi conduzido, são apresentados na Tabela 1. O efeito da interação entre a altura de corte das árvores e as diferentes épocas de avaliação permitiu a determinação de modelos que melhor ajustam os dados, para a estimativa do número médio de brotações por cepa (Tabela 2).

De modo geral, o maior número de brotações foi observado em cepas com altura de 1,20 e $2 \mathrm{~m}$, em ambas as idades dos povoamentos selecionados para os testes. Este fato é explicado pelo acréscimo na área superficial do tronco, que resultou em maior número remanescente de gemas adventícias presentes na cepa. Shackleton (2000) relata que a altura de corte de algumas espécies arbóreas é um fator que pode restringir a capacidade de rebrota das cepas. Segundo esse autor, alturas de corte próximas ao nível do solo favorecem o ataque de fungos degradadores da madeira e, ao mesmo tempo, cepas com alturas elevadas podem reduzir o vigor e o crescimento das brotações.

Considerando-se as estações do ano em que se estabeleceu o corte das árvores com idade de quatro anos, verificou-se maior capacidade de rebrota nos testes instalados durante o inverno e a primavera (junho a novembro). O mesmo comportamento, quanto às estações do ano, foi observado em cepas de sete anos, embora com menor capacidade de rebrota (Tabela 1). As menores médias observadas ocorreram durante o período de verão (dezembro a fevereiro), em ambas as idades avaliadas.

Durante a primavera, os resultados obtidos em cepas de quatro anos, cortadas a $2 \mathrm{~m}$, permitiram estimar o ponto de máxima produção (maior número de brotos por cepa, em função da altura de corte e da época de avaliação) em torno de 59 dias depois do corte, resultando em um número médio de 70 brotações por cepa. Depois deste período, observou-se um decréscimo no número de brotações (Figura $1 \mathrm{~A}$ ).

Quando cortadas durante o verão, cepas com altura de $2 \mathrm{~m}$ atingiram o ponto máximo de produção aos 47 dias depois do corte (Figura $1 \mathrm{~B}$ ), representado por uma média de apenas 30 brotações por cepa, o que indica ser essa época a menos favorável ao corte.

Em estudo desenvolvido por Shimizu (1978), foi constatado que $80 \%$ das árvores de Eucalyptus grandis, na Austrália, apresentaram maior capacidade de rebrota quando cortadas durante a primavera. Para alguns clones de Eucalyptus spp., esse foi também um período

Tabela 1. Análise de variância do número de brotações por cepa, em testes de rebrota de Acacia mearnsii, em povoamentos com quatro e sete anos de idade, nas estações de primavera, verão, outono e inverno.

\begin{tabular}{|c|c|c|c|c|c|c|c|c|c|}
\hline \multirow[t]{3}{*}{ Fonte de variação } & \multirow[t]{3}{*}{ GL } & \multicolumn{8}{|c|}{ Quadrado médio } \\
\hline & & \multicolumn{2}{|c|}{ Primavera } & \multicolumn{2}{|c|}{ Verão } & \multicolumn{2}{|c|}{ Outono } & \multicolumn{2}{|c|}{ Inverno } \\
\hline & & 4 anos & 7 anos & 4 anos & 7 anos & 4 anos & 7 anos & 4 anos & 7 anos \\
\hline Altura de cepa & 5 & $182,25^{*}$ & $34,35^{*}$ & $89,49 *$ & $7,26^{*}$ & $76,61^{*}$ & $11,16^{*}$ & $88,89^{*}$ & $16,41^{*}$ \\
\hline Época de avaliação & 5 & $105,42 *$ & $18,03^{*}$ & $12,25 *$ & $7,97 *$ & $47,07 *$ & $2,76^{*}$ & $10,91^{*}$ & $8,98^{*}$ \\
\hline Altura x Época & 25 & $8,34^{*}$ & $2,33^{*}$ & $1,34^{*}$ & $1,01^{*}$ & $6,71 *$ & $0,83^{*}$ & $1,50 *$ & $1,55^{*}$ \\
\hline Resíduo & 125 & 0,47 & 0,28 & 0,22 & 0,13 & 0,40 & 0,19 & 0,46 & 0,28 \\
\hline Média geral & & 21,1 & 4,2 & 9,3 & 1,6 & 10,1 & 1,8 & 18,3 & 3,0 \\
\hline $\mathrm{CV}(\%)$ & & 3,2 & 12,7 & 5,1 & 22,2 & 6,3 & 24,1 & 3,7 & 17,6 \\
\hline
\end{tabular}

*Significativo a $5 \%$ de probabilidade pelo teste $\mathrm{F}$.

Tabela 2. Estimativa do número médio de brotações (NB) por cepa, em testes de rebrota de Acacia mearnsii, aos quatro e sete anos de idade, em função da altura (H) de corte e da avaliação depois do corte das árvores (D: dias).

\begin{tabular}{|c|c|c|c|}
\hline Estação do ano & Equação & Erro padrão & $\mathrm{R}_{\mathrm{aj}}^{2}$ \\
\hline $\begin{array}{l}\text { Primavera } \\
\text { Verão } \\
\text { Outono } \\
\text { Inverno }\end{array}$ & $\begin{array}{l}4 \text { anos } \\
\mathrm{NB}=-40,5533+0,3545 \mathrm{H}+1,80746 \mathrm{D}-0,0006 \mathrm{H}^{2}-0,0181 \mathrm{D}^{2}+0,0016 \mathrm{HD} \\
\mathrm{NB}=-11,35842+0,1835 \mathrm{H}+0,4745 \mathrm{D}-0,0002 \mathrm{H}^{2}-0,0049 \mathrm{D}^{2}-0,0001 \mathrm{HD} \\
\mathrm{NB}=9,7997-0,1119 \mathrm{H}-0,4465 \mathrm{D}-0,0001 \mathrm{H}^{2}-0,0032 \mathrm{D}^{2}+0,0054 \mathrm{HD} \\
\mathrm{NB}=-10,8715+0,0088 \mathrm{H}+0,7739 \mathrm{D}-0,0006 \mathrm{H}^{2}-0,0089 \mathrm{D}^{2}+0,0031 \mathrm{HD}\end{array}$ & $\begin{array}{r}17,46 \\
5,56 \\
9,67 \\
11,73\end{array}$ & $\begin{array}{l}0,70 \\
0,85 \\
0,83 \\
0,92 \\
\end{array}$ \\
\hline $\begin{array}{l}\text { Primavera } \\
\text { Verão } \\
\text { Outono } \\
\text { Inverno }\end{array}$ & $\begin{array}{l}7 \text { anos } \\
\mathrm{NB}=-10,5694+0,0349 \mathrm{H}+0,5384 \mathrm{D}+0,0003 \mathrm{H}^{2}-0,0051 \mathrm{D}^{2}-0,0005 \mathrm{HD} \\
\mathrm{NB}=-4,4954+0,0227 \mathrm{H}+0,2249 \mathrm{D}+0,0001 \mathrm{H}^{2}-0,0021 \mathrm{D}^{2}-0,0002 \mathrm{HD} \\
\mathrm{NB}=-1,7644+0,0032 \mathrm{H}+0,0913 \mathrm{D}-0,0001 \mathrm{H}^{2}-0,0010 \mathrm{D}^{2}+0,0006 \mathrm{HD} \\
\mathrm{NB}=-6,0106+0,0787 \mathrm{H}+0,2599 \mathrm{D}-0,0001 \mathrm{H}^{2}-0,0022 \mathrm{D}^{2}-0,0009 \mathrm{HD}\end{array}$ & $\begin{array}{l}6,53 \\
2,25 \\
2,12 \\
4,53\end{array}$ & $\begin{array}{l}0,74 \\
0,68 \\
0,87 \\
0,79\end{array}$ \\
\hline
\end{tabular}



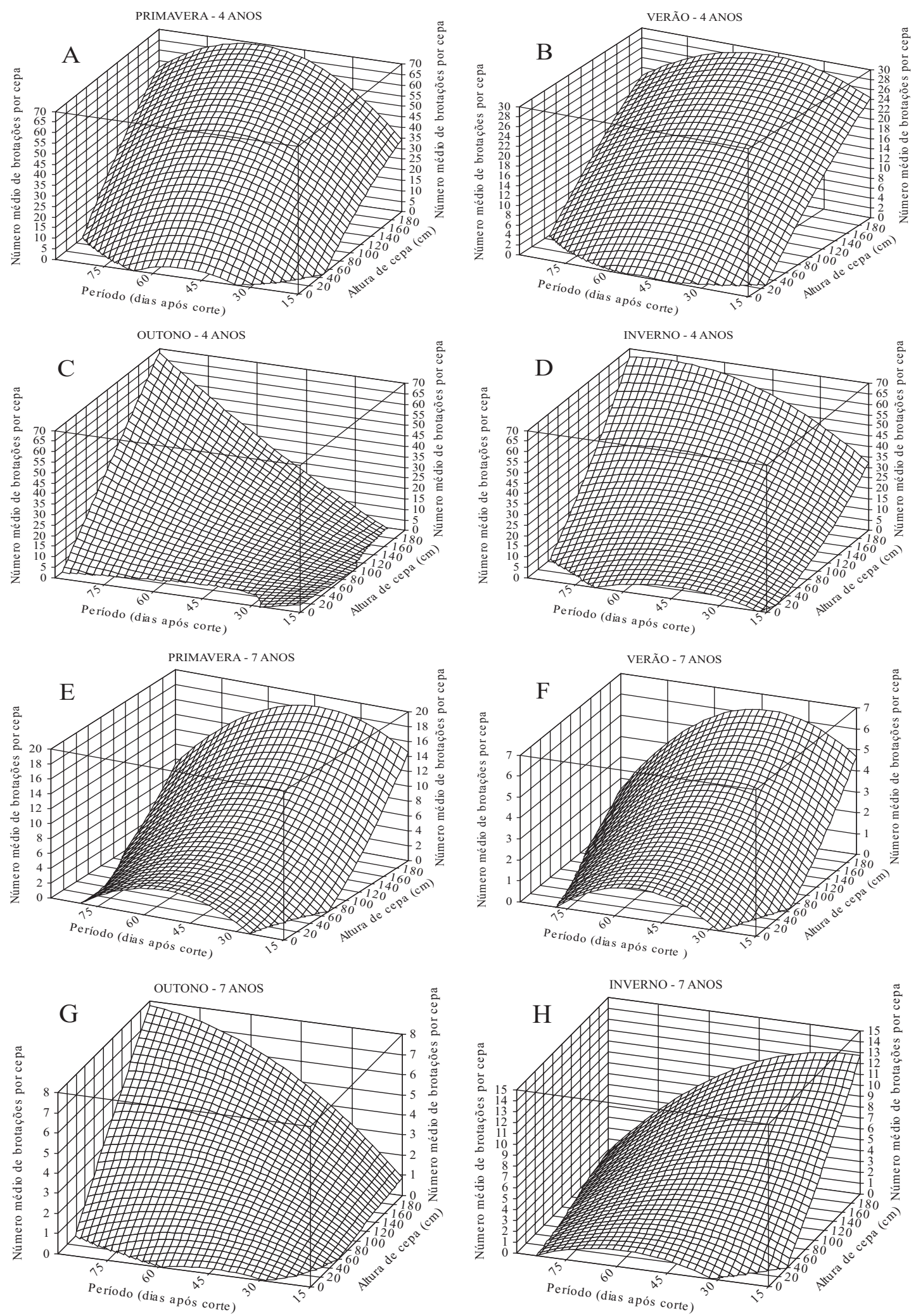

Figura 1. Número médio de brotações, em diferentes alturas de cepas de Acacia mearnsii De Wild., em quatro épocas do ano (primavera, verão, outono e inverno), aos quatro anos (A a D) e sete anos (E a H), no período de 90 dias depois do corte das árvores. 
determinante à rebrota das cepas (Rosse et al., 1997). No entanto, em regiões tropicais e subtropicais, o período do verão é normalmente de maior oscilação da temperatura e da ocorrência de chuvas, o que interfere diretamente na disponibilidade de água no solo. Para Souza et al. (1991), a umidade do solo é um dos principais fatores envolvidos na capacidade de rebrota de cepas. Beck (1999) mencionou esse fator como um agravante à emissão e ao estabelecimento de brotações jovens em cepas principalmente durante o verão uma vez que dependem de índices pluviométricos adequados à reposição e reserva de água no solo. Neste trabalho, a baixa capacidade de rebrota de cepas verificada durante o verão esteve relacionada com a ocorrência de poucas chuvas e altas temperaturas entre os meses de dezembro de 2001 e fevereiro de 2002 (Figura 2).

Adicionalmente, outros fatores como a disponibilidade de substâncias de reserva, podem exercer efeitos sobre a capacidade de rebrota de cepas. Segundo Sakai \& Sakai (1998), em regiões de clima temperado, a rebrota de espécies florestais depois do corte é consideravelmente dependente de substâncias de reserva, como os carboidratos presentes nas raízes da planta. Esses autores mencionam, ainda, que essa dependência é característica da variação na capacidade de rebrota da cepa, que normalmente está atrelada à flutuação estacional da reserva de carboidratos nas raízes. Durante o período de repouso vegetativo da planta são verificados os maiores índices de armazenamento de substâncias de reserva (Hall \& Wray, 1998; Nair et al., 2001). O corte realizado durante este estádio proporciona brotações mais vigorosas e em maior número por cepa, diminuindo sensivelmente essa capacidade de rebrota quando o corte é realizado na estação de ativo crescimento da planta (Ceulemans et al., 1996). A reserva de carboidratos durante o período de crescimento tende a diminuir consideravelmente, sugerindo que substâncias como o amido e outros açúcares são mobilizados para garantir o desenvolvimento da planta (Nair et al., 2001).

Essas constatações podem explicar o comportamento das cepas na estação de verão, independentemente da altura de corte. Considera-se, ainda, que as brotações estiveram também expostas a temperaturas mais elevadas e a condições limitantes de água no solo, podendo ter tido seu desenvolvimento inicial comprometido. Contrariamente, a estimativa do número médio de brotações, verificado em cepas cortadas a 2 m de altura, durante o outono (Figura $1 \mathrm{C}$ ), mostra tendência de aumento mesmo após o período de 90 dias depois do corte, enquanto no inverno o número de brotações teve seu pico aos 78 dias depois do corte, também na altura de 2 m (Figura 1 D).

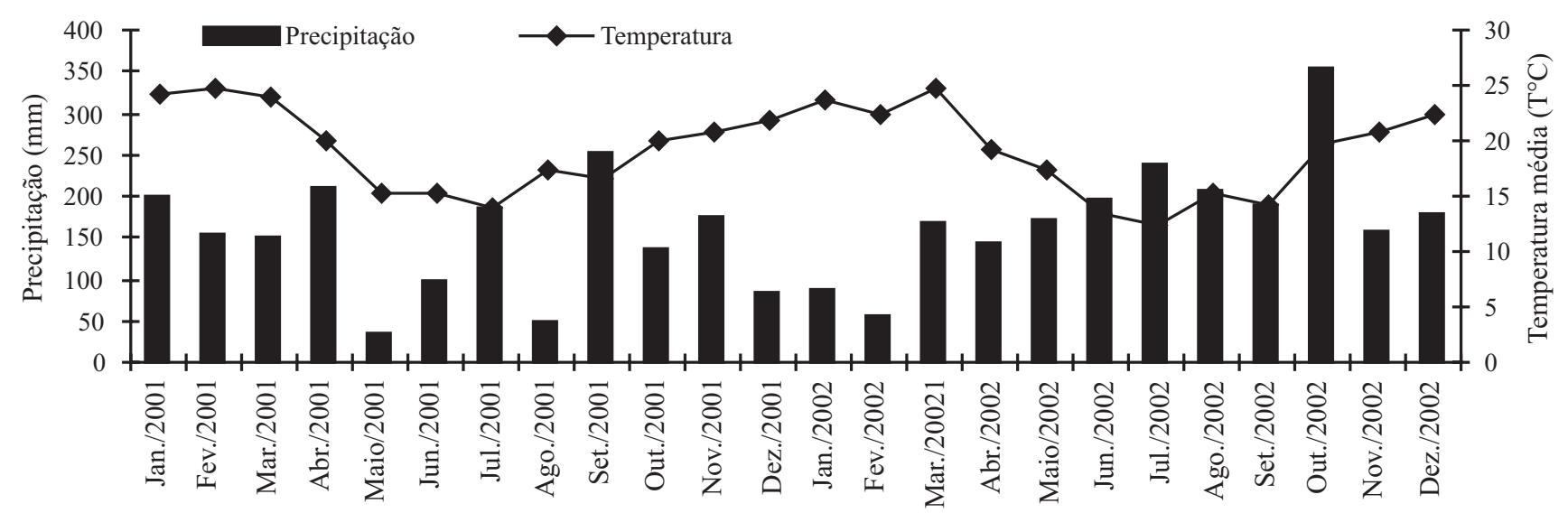

Mês/ano

Figura 2. Precipitação e temperatura média mensal, ocorridas na região de estabelecimento do trabalho, no período de janeiro de 2001 a dezembro de 2002. Fonte: Fepagro (2005). 
Em cepas de sete anos, verificou-se relevante diminuição na média geral de brotações por cepa, ao longo das estações do ano (Tabela 1), quando comparadas com cepas de quatro anos. A idade da planta exerce grande influência sobre a intensidade, o vigor e a sobrevivência das cepas, decrescendo à medida que a planta envelhece (Minore \& Weatherly, 1996). Uma resposta linear para o número de brotações em cepas de A. mearnsii foi verificada por Beck (1999), na África do Sul, com a maior produção aos dois anos e a menor em cepas aos dez anos, ambas cortadas a $1,5 \mathrm{~m}$ de altura.

Na idade de sete anos, a melhor época de corte na altura de $2 \mathrm{~m}$ foi verificada também na primavera, e a menos favorável durante o verão (Figura $1 \mathrm{E}$ e F). Exceto no outono e no inverno, as cepas com $2 \mathrm{~m}$ produziram o maior número de brotações, por volta dos 40 dias depois do corte, decrescendo consideravelmente depois desse período. Aos 75 dias, esse comportamento foi ainda mais acentuado, com a completa ausência de brotações em cepas com alturas inferiores a $2 \mathrm{~m}$, consideradas, a partir de então, como cepas nãosobreviventes (Figura 1 E, F e H).

O desenvolvimento de gemas adventícias, embora em menor número, apresentou o mesmo comportamento daquelas verificadas na idade de quatro anos, porém com longevidade (tempo de permanência na cepa antes de secar) consideravelmente inferior, inclusive na primavera, que apresentou a maior média de brotações por cepa. Verificou-se em cepas com sete anos que o período compreendido entre a emissão das gemas e seu respectivo desenvolvimento na cepa foi relativamente curto. Em alguns casos, como no inverno, o número máximo de brotações por cepa (2 m) foi atingido aos 17 dias depois do corte, tendo resultado em substancial decréscimo depois deste período. Como implicação disso, registrou-se para as cepas de sete anos, os mais altos porcentuais de mortalidade, principalmente nas alturas de corte inferiores a 1,20 m. Esse comportamento pode ser explicado não somente pelo efeito da idade, mas também pela influência do diâmetro das cepas, efetivamente maior, se comparado ao diâmetro das cepas com quatro anos. Não somente a intensidade de rebrota e a sobrevivência das cepas estão relacionados à idade (Minore \& Weatherly, 1996), mas também a capacidade de rebrota de cepas que, segundo Hartney
(1980), reduz-se proporcionalmente à medida que a planta envelhece. Beck et al. (1998) verificaram a rebrota em cepas de A. mearnsii, na África do Sul, em até $50 \%$ de cepas aos dois anos, enquanto em cepas com quatro anos, esse porcentual esteve reduzido a $26 \%$, quando cortadas na altura de $1,5 \mathrm{~m}$.

Na Figura 3, verifica-se a evolução da capacidade de rebrota durante o período intermediário das avaliações (aos 30, 45 e 60 dias) e o estabelecimento das brotações na cepa (aos 90 dias), o que caracteriza sua efetiva sobrevivência. Verificou-se que apenas metade do número total de cepas, com altura de $0,15 \mathrm{~m}$, rebrotou 30 dias depois do corte e que, principalmente na idade de sete anos, os porcentuais de cepas com brotação foram inferiores a $5 \%$. Na altura de $0,15 \mathrm{~m}$, observouse, ainda, uma alta taxa de mortalidade (90 a 95\%), exceto no outono, em que aproximadamente $25 \%$ das cepas mantiveram as brotações por um período mais longo. Possivelmente as menores alturas de corte $(0,15$ a $0,45 \mathrm{~m}$ ) exerceram efeito negativo sobre a sobrevivência das cepas (aos 90 dias depois do corte). Para Johansson (1992), a altura de corte delimita o número de gemas adventícias aptas à rebrota, o que contribui positivamente para a sobrevivência da cepa. Menores alturas de corte podem, também, comprometer a disponibilidade de substâncias de reservas na planta. Embora mais concentrado no sistema radicular, a fonte de carboidratos pode alocar-se ao longo do tronco da árvore, assumindo papel essencial na prevenção ou retardamento da morte da cepa (Sakai et al., 1997; Nair et al., 2001). Contudo, o longo tempo em que a cepa dependerá das substâncias de reserva alocadas no sistema radicular, até estabelecer brotações fotossinteticamente ativas, poderá ser um fator crítico para sua sobrevivência (Hardesty et al., 1988). Em contrapartida, o corte realizado na época ideal, variável entre espécies, promove uma maximização da capacidade de rebrota das cepas e eleva a garantia de sua sobrevivência (Ceulemans et al., 1996).

Os resultados obtidos neste trabalho confirmam a potencialidade do método de obtenção de material juvenil, em cepas de acácia-negra, dentro de programas de melhoramento genético florestal. No entanto, futuras investigações nesta linha de pesquisa devem ser implementadas, sobretudo quanto à elucidação dos aspectos relacionados à clonagem desta espécie florestal. 

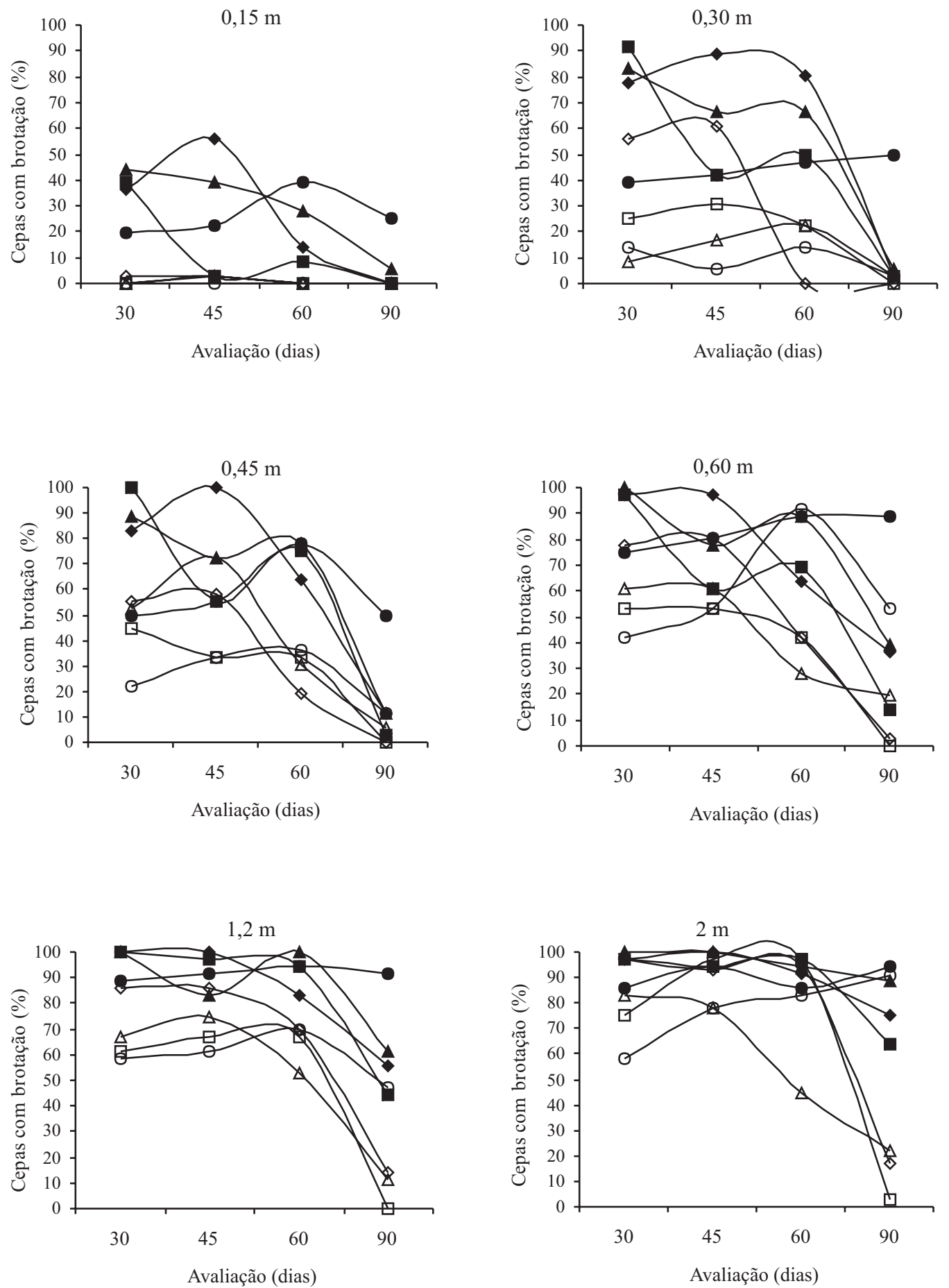

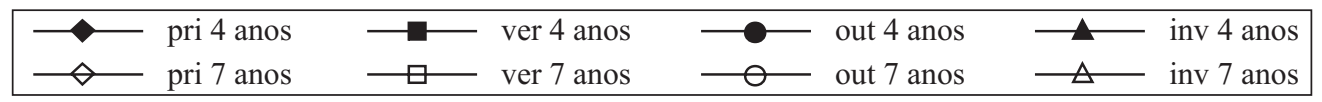

Figura 3. Porcentual médio de cepas de Acacia mearnsii De Wild., com brotações ao longo do período de avaliação (30, 45 e 60 dias) e sobrevivência final (90 dias), nas alturas de corte de 0,15, $0,30,0,45,0,60,1,2$ e $2 \mathrm{~m}$, aos quatro e sete anos, nas estações de primavera (pri), verão (ver), outono (out) e inverno (inv). 


\section{Conclusões}

1. Árvores adultas de Acacia mearnsii apresentam boa capacidade de rebrota, quando cortadas à altura entre 1,2 e $2 \mathrm{~m}$, principalmente na idade de quatro anos.

2. A época mais indicada ao corte compreende o período entre o outono e a primavera, e a menos favorável é o período do verão.

\section{Agradecimentos}

À empresa Agroseta S.A., pela disponibilização de estrutura física, de pessoal e financeira para a realização do trabalho.

\section{Referências}

BECK, S.L. Micropropagation of Acacia mearnsii De Wild. 1999. 126p. Tese (Doutorado) - University of Natal, Pietermaritzburg, África do Sul.

BECK, S.L.; DUNLOP, R.; STADEN, J. van. Rejuvenation and micropropagation of adult Acacia mearnsii using coppice material. Plant Growth Regulation, v.26, p.149-153, 1998.

CEULEMANS, R.; McDONALD, A.J.S.; PEREIRA, J.S. A comparison among eucalypt, poplar and willow characteristics with particular reference to a coppice, growth-modelling approach. Biomass and Bioenergy, v.11, p.215-231, 1996.

FEPAGRO. Estação Meteorológica da Fundação Estadual de Pesquisa Agropecuária. Disponível em: <http:// www.cnpt.embrapa.br/agromet>. Acesso em: nov. 2005.

FOWLER, J.A.P.; CURCIO, G.R.; RACHWAL, M.F.G.; DEDECEK, R.A.; SIMON, A.A. Germinação e vigor de sementes de Acacia mearnsii De Wild. coletadas em diferentes povoamentos do Estado do Rio Grande do Sul. Colombo: EmbrapaCNPF, 1999. 4p. (Comunicado técnico, 39).

HACKETT, W.P. Donor plant maturation and adventitious root formation. In: DAVIS, T.D.; HAISSIG, B.E.; SANKHLA, N. (Ed.). Adventitious root formation in cuttings. Portland: Dioscorides Press, 1988. p.11-28. (Advances in plant science series, 2).

HALL, R.B.; WRAY, P.H. Coppice management of Iowa hardwoods. Ames: Iowa State University, 1998. 4p. (Forestry extension note, F-327).

HARDESTY, L.H.; BOX, T.W.; MALECHEK, J.C. Season of cutting affects biomass production by coppicing browse species of theBrazilian caatinga. Journal of Range Management, v.41, p.477-480, 1988.

HARTNEY, V.J. Vegetative propagation of the Eucalypts. Australian Forest Research, v.10, p.191-211, 1980.

HIGA, R.C.V.; STURION, J.A. Capacidade de brotação em subgêneros e espécies de Eucalytpus. Piracicaba: Ipef, 1997. p.23-30. (Série técnica, v.11, n.30).
HIGASHI, E.N.; SILVEIRA, R.L.V. de A.; GONÇALVES, A.N. Propagação vegetativa de Eucalyptus: princípios básicos e a sua evolução no Brasil. Piracicaba: Ipef, 2000. 12p. (Circular técnica, 192).

JOHANSSON, T. Sprouting of 2- to 5-year-old birches (Betula pubescens Ehrh. and Betula pendula Roth) in relation to stump height and felling time. Forest Ecology and Management, v.53, p.263-281, 1992.

LATT, C.R.; NAIR, P.K.R.; KANG, B.T. Reserve carbohydrate levels in the boles and structural roots of five multipurpose tree species in a seasonally dry tropical climate. Forest Ecology and Management, v.146, p.145-158, 2001.

LUOGA, E.J.; WITKOWSKI, E.T.F.; BALKWILL, K. Regeneration by coppicing (resprouting) of miombo (African savanna) trees in relation to land use. Forest Ecology and Management, v.189, p.23-35, 2004.

MINORE, D.; WEATHERLY, H.G. Stump sprouting of Pacific yew. Portland: U.S. Department of Agriculture, Forest Service, Pacific Northwest Research Station, 1996. 6p. (General technical report, PNW-GTR-378).

REIS, G.G. dos; REIS, M. das G.F. Fisiologia da brotação de eucalipto com ênfase nas suas relações hídricas. Piracicaba: Ipef, 1997. p.9-22. (Série técnica, v.11, n.30).

ROSSE, L.N.; DAVIDE, A.C.; BERTOLUCCI, F. de L.G.; RAMALHO, M.P. Influência da idade e da época de abate na brotação das cepas e no enraizamento de estacas em clones de Eucalyptus sp. Revista Cerne, v.3, p.109-119, 1997.

SAKAI, A.; SAKAI, S. A test for the resource remobilization hypothesis: tree sprouting using carbohydrates from above-ground parts. Annals of Botany, v.82, p.213-216, 1998.

SAKAI, A.; SAKAI, S.; AKIYAMA, F. Do sprouting tree species on erosion-prone sites carry large reserves of resources? Annals of Botany, v.79, p.625-630, 1997.

SHACKLETON, C.M. Stump size and the number of coppice shoots for selected savanna tree species. South African Journal of Botany, v.66, p.124-127, 2000.

SHIMIZU, J.Y. Aspectos da atividade florestal e de pesquisas correlatas na Austrália e Papua - Nova Guiné. Brasil Florestal, v.9, p.42-57, 1978.

SOUZA, A.J.; ZEN, S.; GIBERTONI, P.E.; SANCHEZ, O.A. Observações preliminares de alguns fatores que afetam a brotação do eucalipto. Piracicaba: Ipef, 1991. 6p. (Circular técnica, 177).

TEWARI, S.K.; KATIYAR, R.S.; RAM, B.; MISRA, P.N. Effect of age and season of hasvesting on the growth, coppicing characteristics and biomass productivity of Leucaena leucocephala and Vitex negundo. Biomass and Bioenergy, v.26, p.229-234, 2004.

WENDLING, I.; XAVIER, A. Gradiente de maturação e rejuvenescimento aplicado em espécies florestais. Floresta e Ambiente, v.8, p.187-194, 2001.

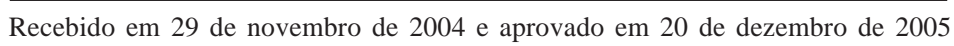

